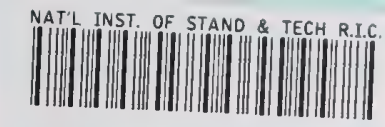

A】II04 ?】2845

NISTIR 5686

\section{NIST \\ PUBLICATIONS}

\title{
Algorithm Testing and Evaluation Program for Coordinate Measuring Systems: Testing Methods
}

Cathleen Diaz

U.S. DEPARTMENT OF COMMERCE

Technology Administration

National Institute of Standards and Technology

Manufacturing Engineering Laboratory

Manufacturing Systems Integration Division

Gaithersburg, MD 20899-0001

QC

100

.056

N0.5686

1995 

NISTIR 5686

\section{Algorithm Testing and Evaluation Program for Coordinate Measuring Systems: Testing Methods}

Cathleen Diaz

\section{U.S. DEPARTMENT OF COMMERCE}

Technology Administration

National Institute of Standards and Technology

Manufacturing Engineering Laboratory

Manufacturing Systems Integration Division

Gaithersburg, MD 20899-0001

July 1995

\section{U.S. DEPARTMENT OF COMMERCE}

Ronald H. Brown, Secretary

TECHNOLOGY ADMINISTRATION

Mary L. Good, Under Secretary for Technology

NATIONAL INSTITUTE OF STANDARDS AND

TECHNOLOGY

Arati Prabhakar, Director

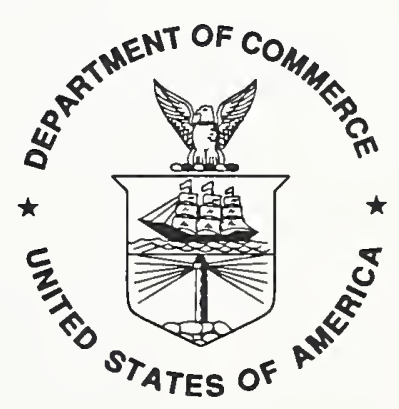





\section{NOTICE}

This document was developed by an employee of the National Institute of Standards and Technology (NIST), a U.S. Government agency, as part of her official duties and is, therefore, not subject to copyright.

\section{DISCLAIMER}

Commercial products, equipment, or materials are identified in this document in order to facilitate understanding. Such identification does not imply recommendation or endorsement by the National Institute of Standards and Technology, nor does it imply that the products identified are necessarily the best available for the purpose. 


\section{ACKNOWLEDGEMENTS}

The funding provided by The National Institute of Standards and Technology and the Office of Measurements Services Calibration Program has made the continuation of this project possible. Their support is appreciated. Special thanks to Dr. Joe Simmons, Chief of the Calibration Program for his faith and support in this work. In addition, I want to acknowledge the outstanding work of the members of the American Society of Mechanical Engineers (ASME), B89.4.10 Working Group for Coordinate Measuring Systems Software Performance Evaluation, NIST colleagues at the Computing and Applied Mathematics Laboratory, and the dedicated efforts of the project team, Dr. Theodore H. Hopp, David Rosenfeld, and Ann Nishioka of the NIST Manufacturing Systems Integration Division. In addition, special thanks to Dr. Hopp for his valuable contributions towards the editing and organizing of this report. 


\title{
Algorithm Testing and Evaluation Program for Coordinate Measuring Systems: Testing Methods ${ }^{\dagger}$
}

\author{
Cathleen Diaz \\ National Institute of Standards and Technology \\ Gaithersburg, MD 20899-000I ${ }^{\dagger \dagger}$
}

\section{Introduction}

The NIST Algorithm Testing and Evaluation Program for Coordinate Measuring Systems (ATEP-CMS) evaluates the performance of data analysis software used in coordinate measuring systems. ATEP-CMS is available through the NIST Calibration Program as Special Test numbers 10070S (special test of CMS software with NIST-generated data sets) and 10080S (special test of CMS software with customer-generated data sets). ATEP-CMS supports the following geometry types: circle, line, plane, sphere, cylinder, cone, and torus.

This report details the CMS testing and evaluating methods that ATEP-CMS uses to test and evaluate the performance of CMS software. It is intended as a guide to procedures for ATEP-CMS testing personnel.

Section 2 of this report discusses the specific test methods for carrying out an ATEP-CMS request. Section 3 describes the general principles, methods, and practices for testing the performance of CMS software. This report also contains appendices that provide information on the characteristics by which CMS software performance is evaluated, a template of a special test report, and other pertinent information.

\section{Specific Test Procedures}

This section describes the specific steps that must be carried out in order to test a CMS software package. The emphasis in this section is on the administrative and logistical aspects of the test. Technical aspects of the activities are discussed in Section 3. This section provides crossreferences to Section 3 and references to other documents as needed.

ATEP-CMS customer requests are received through the Manufacturing Systems Integration Division (MSID) of NIST. The customer and MSID discuss the details of the customer's testing needs and MSID's testing options. The customer and MSID agree on the ranges of parameters (geometry types, form errors, measurement errors, and sampling plans) to be used in defining the customer's test experiments (details provided in Section 3.2). The customer sends MSID a purchase order requesting ATEP-CMS service. MSID directs the purchase order to the Calibration Program (CP) for handling. CP then provides MSID with a formal test folder. Following are the phases and detailed descriptions of the steps to follow in completing a customer's request for ATEP-CMS service. ATEP-CMS testing personnel carry out the instructions printed in italics. The descriptions following the italicized instructions provide details and cross-references to Section 3 where appropriate.

States.

${ }^{\dagger}$ Contribution of the National Institute of Standards and Technology; not subject to copyright in the United

${ }^{\dagger+}$ Manufacturing Systems Integration Division 


\section{Phase I: Handling the test service request}

1. Log receipt of the test folder for each ATEP-CMS request $M S I D$ receives from $C P$. The test folder includes a serially numbered test form (form number NIST 64) and the customer's purchase order. The test form has six parts, to allow appropriate record keeping at each office. These six parts are as follows:

- 1- acceptance form;

- 2- division record form;

- 3- fee record form;

- 4- shipping record form;

- 5- packing slip form;

- 6- CP record form.

MSID receives copies \#1 - \#5 of the test form. CP retains copy \#6 for their records. Please note that all technical, administrative, and scheduling aspects of the test should be recorded throughout the testing process.

2. Send the acceptance form copy of the test form to the customer. This form includes the estimated cost for the service requested, an estimated date for the customer to expect receipt of the data sets, and an estimated date for the completion of the test. The fee schedule can be obtained from the $\mathrm{CP}$ office.

\section{Phase II: Setting up the test}

3. Design specific values for test description definitions and number of tests for each geometry ordered. Any form errors, sampling plans, and measurement errors are defined at this time. For technical details refer to Section 3.2: Designing test descriptions.

4. Create experiment and enter test definitions in the NIST Algorithm Testing System (ATS) $[3,4]$. For technical details refer to Section 3.3.1: Entering test definitions, steps 1-4.

5. Generate data sets from test definitions. (Fit results can be generated at this time and saved for when customer's fit results are returned). For technical details see Section 3.3.1: Entering test definitions, step 5.

6. Export data sets to file formats defined by customer. Keep backup copies of all data sets. For details see Section 3.3.2: Exporting and Mailing Data Sets.

7. Mail data sets to customer with instructions. Indicate format requirements for fit results. Include copy \#4 of the test form with the diskette. For details see Section 3.3.2: Exporting and Mailing Data Sets.

\section{Phase III: Receiving fit results}

8. Log receipt of diskette with customer's fit results. 
9. Send acknowledgment of receipt of diskette with fit results to customer.

10. Import customer's fit results into the ATS under the customer's previously defined experiment. If there are any problems, contact the customer to resolve them. For details see Section 3.3.3: Importing Customer's Data.

\section{Phase IV: Testing fit results}

11. Generate reference fits with the ATS. If reference fits were generated during step 5 above, then this step is skipped. For technical details see the ATS's users guide, the reference manual $[3,4]$, and the ATS on-line help.

12. Run the necessary analyses. For technical details see Section 3.3.4: Run Analyses and Prepare Special Test Report and the ATS on-line help.

13. Save results and secure files.

14. Note discrepancies, resolve with customer and repeat tests and analyses as necessary.

\section{Phase V: Preparing Special Test Report}

15. Prepare Report of Special Test Service. Refer to Section 3.3.4: Run Analyses and Prepare Special Test Report. Also see Appendix C for a template of the Special Test Report.

16. Secure Report of Special Test Service and all related fit result files.

17. Obtain appropriate signatures (if required, OU director and division chief). Minimally, the calibration supervisor needs to sign the report.

18. Send the diskette with the results and the printed Special Test Report to the customer. Include copy \#5 of the test form in the package sent to the customer.

\section{Phase VI: Requesting payment}

19. Indicate on the fee record form of the test form (copy \#3) the fee to be charged along with the cost center.

20. Retain division form copy of the test form (copy \#2) for record within the division.

21. Forward the test form with completed work to CP for filing (copy \#3 of the test form). $\mathrm{CP}$ audits fee record (test form copy \#3) and sends it to the Office of the Comptroller for billing. After billing, Office of the Comptroller returns the fee record to $\mathrm{CP}$ for filing.

22. Log completion of service to customer. Record technical, administrative, and scheduling aspects of the test. 


\section{Test Methodology}

This section describes the test methodology used in ATEP-CMS. This section provides the underlying technical details for Section 2, a description of the general principles, the methods, and the practices for testing the performance of CMS software.

ATEP-CMS evaluates CMS software strictly in terms of its intended function. The software is considered to be a "black box" that is subjected to variations of inputs while outputs are evaluated with respect to a specific objective. This functional testing determines how well the software does what it is supposed to do. This is done by designing data sets which reflect the expected range and variability of actual data. The NIST Algorithm Testing System (ATS) is the tool used to perform the functional testing.

Data formats, data resolution, and related characteristics of the test are subject to agreement between the customer and NIST.

\subsection{The Testing Tool: Algorithm Testing System (ATS)}

\subsubsection{Overview}

The ATS consists of three major components: a data generator, a set of reference algorithms, and a fit analysis module. The data generator produces data sets based on a test description provided by the ATS operator. A test description consists of ranges of values for each of four information classes:

1. nominal (ideal) geometry of the feature;

2. form errors of the feature being simulated;

3. sampling plan (number and location of points on the feature);

4. measurement errors statistical distribution of the points.

The data sets are processed by the software under test to generate test fits and by ATS algorithms to generate reference fits. The fits are analyzed in terms of geometric differences among the fits. Test fits and reference fits are compared to evaluate the geometric differences between them. The data sets, test fits, and reference fits are used to assess the performance of the software under test.

The ATS features the following implementations:

- least-squares fitting algorithms;

- 3-D Least-squares for circles;

- minimum-radius circumscribed for circles and spheres;

- data generation with simulated form errors, measurement errors, and sampling plans;

- window-based user interface;

- on-line help;

- data management capabilities;

- residual analysis of a fit;

- detailed comparison of fit results; 
- graphical display of data sets and fit results;

- printing capabilities;

- detailed report of results.

For specific technical details regarding how to run the ATS and how to create an experiment for CMS software performance testing, please refer to the Reference Manual for the Algorithm Testing System Version 2 [3], and the User's Guide for the Algorithm Testing System Version 2 [4].

\subsubsection{Functions of the ATS}

The following subsections briefly describe the basic functions of the ATS.

\subsubsection{Test Definition}

Test definitions describe the geometric features to be fitted. The test definition contains the nominal geometry, the form errors, the sampling plan, and the measurement errors to be simulated. In the ATS, the test definition is defined after starting an experiment and selecting a geometry type. Once the new test definition is inserted, the user interface for describing the test is provided. Data is entered for each of the information classes.

\subsubsection{Data Generator}

The data generator is used to generate data sets for specified feature types with controlled range and variability as well as the known solution for some types of features. The data generator uses the test description as input to generate the test data.

\subsubsection{Internal Algorithms}

The ATS contains internal fitting algorithms. These internal algorithms are used to generate reference fits corresponding to specific data sets. Currently, the ATS implements least-squares for all geometric elements, 3-D least squares for circles, and minimum circumscribed algorithms for circles and spheres.

\subsubsection{Data Import and Export}

The ATS incorporates means to transfer data sets to the software under test, and to receive fit results from the software under test. The formats required are detailed in Appendix B of the draft national standard, ASME B89.4.10 [1], and in the ATS reference manual [3].

\subsubsection{Fit Analysis}

The fit analysis module is used for comparing the results of the software under test to the reference results with respect to the objective function. The comparison is based on the geometric differences between the test fits and the reference fits.

\subsection{Designing test descriptions}

In order to design test descriptions for a particular test request NIST testing personnel needs to have some knowledge of the typical CMS inspection scenarios that the customer works with. This 
section provides a checklist of the information that NIST testing personnel should ask the customer for before designing a test description. Some examples of the type of information customers might provide are listed within the checklist. Several of these items may have different answers for each geometry type.

What is the number of data sets typically used?

EXAMPLE: 20 data sets, 100 data sets, 2000 data sets, etc.

What unit of measurement is used?

EXAMPLE: inches, millimeters, etc.

What geometric element types are of interest?

EXAMPLE: line, circle, plane, sphere, cone, cylinder, torus.

What is the range of part sizes typically seen?

EXAMPLE: Customer has small and large parts that fill most of the space in an inspection tray. Small parts are about 20 or $30 \mathrm{~mm}$. Large parts are about $1 / 2$ the working volume or more in each dimension.

$\square$ Where should the part origin be, at the center of the part or at a distance away from the origin?

EXAMPLE: Origin is typically 10 meters away from the part origin.

How many significant digits are to be considered in the test?

EXAMPLE: Resolution of $10^{-6}$ meter

How many data sets per geometry should be generated?

EXAMPLE: 50 data sets per geometry type

What kind of form errors are typically seen on parts? (This may vary with the geometry types).

EXAMPLE: random, sine, step, bends, etc.

What sampling strategy is used? How many points are taken with each measurement? (This will vary with the geometry type).

EXAMPLE: random, equispaced, stratified

What measurement errors are typically seen?

EXAMPLE: uniform, normal

If testing circles, are all the circles in the $\mathrm{x}-\mathrm{y}$ plane or are the circles skewed?

Are there partial features for each kind of geometry type to be tested? 
In general, circle geometry types are difficult to test because the circle could be skewed or not. Planes, spheres, and tori are generally simple to test. Cones and cylinders are complicated by the large range of form errors possible. The ATS reference manual and user guide [3,4] provide the technical detail necessary to design geometric features with form errors, measurement errors, and sampling strategies.

\subsection{Steps for CMS software performance evaluation}

\subsubsection{Entering Test Definitions}

The data sets to be used to generate reference fit results are generated by either the ATS or the customer. If the data sets are customer-generated there is no need to enter a test definition. (Test definitions are necessary for generating data sets in the ATS). The customer-generated data sets must be verified for appropriate format and then imported into the ATS. For data set file formats please refer to Appendix B of the national draft standard, ASME B89.4.10 [1] and the ATS reference manual [3]. Also note that the ATS provides on-line help for all of its functions.

If the data sets are to be generated with the ATS, the following five steps must be followed. The actual data entered into the ATS depends on the information gathered from the checklist prepared in section 3.2.

Step 1. Run the ATS and define the nominal geometry for the specified feature. The parameters will vary depending on the geometry. The following table provides a general guideline of the parameters required for each geometry. Use this table as a reference when going through the checklist in section 3.2 with the customer.

\begin{tabular}{||c|c|c|c|c|c|c|c||}
\hline & line & circle & planes & sphere & cylinder & cone & torus \\
\hline location & $\mathrm{x}$ & $\mathrm{x}$ & $\mathrm{x}$ & $\mathrm{x}$ & $\mathrm{x}$ & $\mathrm{x}$ & $\mathrm{x}$ \\
\hline direction & $\mathrm{x}$ & $\mathrm{x}$ & $\mathrm{x}$ & & $\mathrm{x}$ & $\mathrm{x}$ & $\mathrm{x}$ \\
\hline size & & $\mathrm{x}$ & & $\mathrm{x}$ & $\mathrm{x}$ & $\mathrm{x}$ & $\mathrm{x}$ \\
\hline angle & & & & & & $\mathrm{x}$ & \\
\hline extent & $\mathrm{x}$ & $\mathrm{x}$ & $\mathrm{x}$ & $\mathrm{x}$ & $\mathrm{x}$ & $\mathrm{x}$ & $\mathrm{x}$ \\
\hline
\end{tabular}

Step 2. Define form errors to be simulated. Form errors simulate part form errors that the customer typically sees in their manufactured parts. The ATS simulates random, sinusoidal, step, and bend errors. These form errors are also specific to the geometry type. Use the following two tables as guidelines when going though the checklist in section 3.2 with the customer and when designing the test description. 


\begin{tabular}{||l|c|c|c|c|}
\hline & random & sine & step & bend \\
\hline line & $\mathrm{x}$ & $\mathrm{x}$ & $\mathrm{x}$ & $\mathrm{x}$ \\
\hline circle & $\mathrm{x}$ & $\mathrm{x}$ & $\mathrm{x}$ & \\
\hline plane & $\mathrm{x}$ & $\mathrm{x}$ & $\mathrm{x}$ & $\mathrm{x}$ \\
\hline sphere & $\mathrm{x}$ & $\mathrm{x}$ & & \\
\hline torus & $\mathrm{x}$ & $\mathrm{x}$ & & \\
\hline
\end{tabular}

\begin{tabular}{||c|c|c|c|c|c|c|c|c||}
\hline random & $\begin{array}{c}\text { axis } \\
\text { sine }\end{array}$ & $\begin{array}{c}\text { axis } \\
\text { bend }\end{array}$ & $\begin{array}{c}\text { axis } \\
\text { step }\end{array}$ & $\begin{array}{c}\text { surface } \\
\text { sine }\end{array}$ & $\begin{array}{c}\text { radius } \\
\text { taper } \\
\text { along } \\
\text { axis }\end{array}$ & $\begin{array}{c}\text { radius } \\
\text { step } \\
\text { along } \\
\text { axis }\end{array}$ & $\begin{array}{c}\text { radius } \\
\text { step } \\
\text { around } \\
\text { axis }\end{array}$ \\
\hline cylinder & $\mathrm{x}$ & $\mathrm{x}$ & $\mathrm{x}$ & $\mathrm{x}$ & $\mathrm{x}$ & $\mathrm{x}$ & $\mathrm{x}$ & $\mathrm{x}$ \\
\hline cone & $\mathrm{x}$ & $\mathrm{x}$ & $\mathrm{x}$ & $\mathrm{x}$ & $\mathrm{x}$ & $\mathrm{x}$ & $\mathrm{x}$ & $\mathrm{x}$ \\
\hline
\end{tabular}

Step 3. Identify the sampling plan (acquire from the customer) to be simulated. The ATS simulates the following sampling methods.

- random

- equispaced

- stratified

Random sampling means that each data point is selected at random from within the extent of the geometry. For circles and lines, a uniformly-distributed random number is generated. For surfaces, two random numbers are generated.

Equispaced sampling means that the surface is divided into a grid by dividing the extent into bins according to the number of points indicated. One point is selected at the center of each grid box.

Stratified sampling is similar to equispaced sampling. Rather than sampling at the center of each box, however, each sample point is obtained by generating a uniformly-distributed random number (or two numbers, for surfaces) between the limits of the grid box.

Step 4. Identify the measurement errors (acquire from the customer) to be simulated, if any. The ATS simulates the following types of measurement errors.

- uniform

- normal 
Measurement error is a displacement of a sampled point in a random direction in three dimensions. The ATS adds a measurement error to each sample point after it is generated. The measurement error at a point is independent of the error at any other point, and $s$ also independent of the geometry. All measurement errors are random. You can control whether measurement errors are to be added, and you can define a scale for the distribution of the measurement error.

Step 5. Generate data sets. The ATS provides a function for generating the data sets. The ATS also provides the option to generate fit results while generating the data sets. Filename defaults are provided for the data sets and the fits but can be overridden by the ATS user.

Generated test data sets will be typical of data normally acquired by the CMS. The data resolution must be considered when generating data sets. The resolution of input data should match the resolution of the CMS scale systems. Testing personnel should make sure the customer has described in detail the CMS scale systems typically used by the customer.

\subsubsection{Exporting and Mailing Data Sets}

ATS-generated data sets prepared for a specific customer experiment are exported from the ATS to files of ASCII text representations of the data. The ATS provides a function for exporting the data sets. The ATS also provides a function to save generated data sets. Save backups of all data sets generated by the ATS. The ATS generates a separate file for each data set. Each data set file produced by the ATS contains a data set identification name, a geometry type label, the date the data set was generated, the number of points represented in the file, and the coordinates of the data. For further details and examples please see Section B.3.1 of Appendix B in the ASME B89.4.10 draft national standard, B89.4.10 [1] and the ATS reference manual [3]. If the customer defined file formats for receiving the data sets, export the data sets to the specified format.

Once the data sets are exported, MSID mails the customer a diskette contain the data set files and an instruction sheet for the customer. Please refer to Appendix A for a copy of the instruction sheet.

\subsubsection{Importing Customer's Data}

After the customer runs the test software using the ATS-generated data sets the fit results are shipped back to NIST to complete evaluation of the customer's CMS software. Fit results are verified to assure appropriate format. Details on the appropriate file formats are found in the ASME B89.4.10 draft national standard [1]. The ATS provides a function for importing data sets and fit results. Refer to the ATS reference manual [3] for further details.

For customer-generated data sets, customers also provide NIST with corresponding fit results. Both the data sets and the fits are imported to the ATS. NIST then generates reference fit results for the data sets provided and compares the reference fits to the customer's fits.

\subsubsection{Run Analyses and Prepare Special Test Report}

The customer's test fit results are compared to the ATS's reference results. The parameters compared vary with the type of geometry. For more details on the parameters compared for each 
type of geometry refer to Appendix B of this document.

The comparison is the geometric difference between the test fits and the reference fits. The computations for the geometric difference depend on the geometry type. The guidelines for algorithm comparison in Section 4.1 and the specifications for reporting test results in Section 5.5 of the ASME B89.4.10 draft national standard [1] are used to compare the results of the software under test to the reference results and to prepare the Special Test Report.

The ATS provides an analysis as a result of the comparison. For technical details refer to the ATS reference manual [3], the ATS online help, and the report Performance Measures for Geometric Fitting in the NIST Algorithm Testing and Evaluation Program [2].

The Special Test Report is prepared after the comparisons are completed. The Special Test Report includes the following:

- the geometric feature types tested;

- the range of conditions represented by the test data;

- characteristics of the software under test computing environment, software version, etc.;

- the root-mean-square deviations between the software under test and the reference results;

- uncertainty of the observed average deviations.

For more details see the Special Test Report template in Appendix C. 
Appendix A:

\title{
Customer \\ Instruction Sheet
}

\author{
Template
}





\section{Customer Instruction Sheet}

The following instructions are intended for the customer personnel who will be running the CMS software to be tested. A DOS formatted diskette containing files with NIST-generated data sets is enclosed. The files contain data sets of 3-dimensional coordinate values generated by the NIST Algorithm Testing System (ATS). All file formats are ASCII text representations of the data. All instructions for the customer personnel are listed in italics. The descriptions following the italicized instructions provide supporting details. Please follow all instructions carefully.

The NIST-generated data sets are intended to be used as input data to the CMS software to be tested. The CMS software under test produces fit results corresponding to the NIST-generated data sets.

Step 1. Copy the NIST-generated data sets from the enclosed diskette to your system. Note that more than one diskette may be included. The diskette contains a separate file for each data set. The data set files have the following format:
Line 1: ID
GEOMETRY_TYPE
DATE
Line 2: COUNT
Line 3: COORDINATES
Line 4: COORDINATES

In Line 1, ID is an identifier string of no more than 32 characters that uniquely identifies the data set. GEOMETRY_TYPE is a label of the geometry type represented by the data. The geometry types currently supported in ATEP-CMS are circles, cones, cylinders, lines, planes, spheres, and tori. DATE is the date on which the data file was generated, represented in the format: dd-mmm-yyyy (e.g., 26-APR-1995).

On Line 2, COUNT is an integer count of the number of points represented in the rest of the file. Starting on Line 3, each remaining line represents one point of the data set, using three Cartesian coordinate values in order $\mathrm{X}, \mathrm{Y}$, and $\mathrm{Z}$. The coordinate values are dimensionless, but are all to the same scale. Coordinate values are represented in decimal floating point notation, separated by spaces. The coordinate values are represented with as many digits as necessary to represent the values to the resolution used in generating the data. Each line is terminated by an end-of-line sequence (ASCII codes 13 and 10) following the $\mathrm{Z}$ coordinate value. After the end-of-line sequence for the last point, the file ends.

Step 2. Convert the NIST-generated data set files to the format required by the CMS software under test. This step is unique to each individual CMS software used by the customer.

Step 3. Download the data sets to the CMS software under test. This step is unique to each individual CMS software used by the customer.

Step 4. Run the CMS software under test and produce fit results for each data set. This step is unique to each individual CMS software used by the customer.

Step 5. Convert the fit results to the file format specified by NIST. Fit results are returned to NIST 
in files formatted according to the geometry type. Each file represents a single fit result for a single data set. The first line of the fit result file should be a copy of the first line of the data set file from which the fit was calculated. The remainder of the file contains the parameters of the fit.

The parameters and their expected sequence in the file are described below. Parameter values must be separated by white space. (White space consists of one or more of the ASCII codes for space, tab, carriage return, line feed, or form feed.) Any line after the first may contain comments. A comment starts with a semicolon (;) and continues to the end of the line. Comments are treated like white space. All position and size parameters are dimensionless, but must be reported in the same scale as the data set coordinates. All angle values must be in decimal degrees. Parameters may appear in decimal floating point or exponential (i.e., $\pm x . x x e \pm x x$ ) notation. The precision of the parameters is assumed to be exact; that is, the values are assumed to include trailing zeroes to infinity. ${ }^{\dagger}$

The fit parameters expected in result files correspond to the parameterization used in the ATS to calculate the difference between fits. These parameters and their expected sequence in the file are shown in the following table:

\begin{tabular}{|c|c|c|c|c|c|c|c|c|}
\hline \multicolumn{2}{|c|}{ Parameter } & Line & Plane & Circle & Sphere & Cylinder & Cone & Torus \\
\hline \multirow{3}{*}{ : } & $\mathbf{X}$ & 1 & 1 & 1 & 1 & 1 & 1 & 1 \\
\hline & $\mathbf{Y}$ & 2 & 2 & 2 & 2 & 2 & 2 & 2 \\
\hline & $\mathbf{Z}$ & 3 & 3 & 3 & 3 & 3 & 3 & 3 \\
\hline \multirow{3}{*}{ 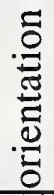 } & $\mathbf{X}$ & 4 & 4 & 4 & & 4 & 4 & 4 \\
\hline & $\mathbf{Y}$ & 5 & 5 & 5 & & 5 & 5 & 5 \\
\hline & $\mathbf{Z}$ & 6 & 6 & 6 & & 6 & 6 & 6 \\
\hline \multirow{2}{*}{ 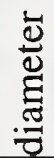 } & major & & & 7 & 4 & 7 & & 7 \\
\hline & minor & & & & & & & 8 \\
\hline \multicolumn{2}{|c|}{ position } & & & & & & 7 & \\
\hline \multicolumn{2}{|c|}{ half-angle } & & & & & & 8 & \\
\hline
\end{tabular}

NOTES: (1) The position parameter for lines is any point on the line; for cylinders it is any point on the axis; for planes it is any point on the plane.

(2) The orientation parameters must be proportional to the direction cosines for the indicated direction. For circles, planes, and tori, the orientation is that of the normal to the plane of the fit.

(3) The position parameter for a cone is the perpendicular distance from the midpoint of the bounded axis to the surface of the cone.

${ }^{\dagger}$ Since fit comparisons involve calculation of geometric differences, rather than direct comparison of parameter values, fit parameters should be expressed in as much precision as possible. In particular, it is important to not round the fit parameters to the apparent resolution of the data set. 
Step 6. Copy fit result files onto diskettes and ship to NIST. If the files are shipped to NIST in a format other than the specified by NIST, please provide a file format description. Following is the shipping address to be used:

ATEP-CMS Special Test Service

National Institute of Standards and Technology

Building 220, Room A127

Gaithersburg, MD 20899-0001

If at any time there are questions or problems, please contact the NIST Manufacturing Systems Integration Division. Contact people are:

Cathleen Diaz

(301) $975-2889$

diaz@cme.nist.gov
Ted Hopp

(301) 975-3545

hopp@cme.nist.gov 
Appendix B:

\section{Software Performance Characteristics}




\section{Appendix B: Software Performance Characteristics}

ATEP-CMS is concerned with the performance characteristics that affect the uncertainty of measurement results produced by CMSs. Quality and reliability are two of these software performance characteristics. For more technical details on this section please refer to the national draft standard, ASME B89.4.10 [1].

\section{Evaluation of Quality}

ATEP-CMS measures the performance of geometric fitting software used in CMSs. Geometric fitting is the process of computing the representation parameters of a geometric element that in some sense best represents a set of point coordinate data (substitute geometry). ATEP-CMS provides quantitative measures of performance. This measurement provides inspection planners with the quantitative measures of performance needed to develop uncertainty budgets and to evaluate the quality of measurement results.

In summary, the performance measures used in ATEP-CMS quantify how well the software computes substitute geometries over a range of inspection problems [2]. The goal is to provide to a user of the software information necessary to decide whether the software is adequate for a particular application. As a result, the following criteria in developing ATEP-CMS performance measures are used:

- each measure should be directly related to inspection tasks;

- each measure should combine like a standard deviation with other sources of uncertainty in a CMS;

- each measure should have reasonable probability and coverage interpretations;

- an estimate of uncertainty should be derivable for each measure.

\section{Evaluation Parameters} follows.

Each geometry type has a unique set of evaluation parameters. Test results are reported as

\section{LINE}

a. the largest separation distance from the bounded test line to the reference line

b. the angle between the test and reference features

\section{CIRCLE}

a. the absolute difference between the radii of the test and reference circles

b. the distance between the centers of the test and reference circles

c. the angle between the planes of the test and reference circles if applicable

\section{PLANE}

a. the largest separation distance from the bounded test plane to the reference plane

b. the angle between the test and reference planes 


\section{SPHERE}

a. the absolute difference between the radii of the test and reference spheres

b. the distance between the centers of the test and reference spheres

\section{CYLINDER}

a. the absolute difference between the radii of the test and reference cylinders

b. the maximum distance from the bounded test cylinder axis to the axis of the reference cylinder

c. the angle between the axes of the test and reference cylinders

\section{CONE}

a. For each cone, the perpendicular distance from the midpoint of the bounded axis to the corresponding cone surface is computed. The evaluation parameter is the absolute difference between these distances.

b. the maximum distance from the bounded test axis to the reference axis

c. the angle between the test and reference axes

d. the absolute difference between the test and reference included cone angles

\section{TORUS}

a. the absolute difference between the major radii of the test and reference torus and the minor radii of the test and reference torus.

b. the distance between the centers of the test and reference torus

c. the angle between the planes of the test and reference torus

\section{Characteristics of Reliability}

Reliability measures the size of the class of problems that the software can solve. The objective is to determine the sensitivity of CMS software to variations of the input data. Reflected in the input data are variations in the following factors:

\section{FEATURE GEOMETRY}

Notably feature size and location may affect the behavior of CMS software. Data analysis software may be less reliable for large size or features located far from the origin.

\section{FEATURE FORM ERROR}

Feature form errors (e.g., straightness, roundness, cylindricity, etc.) affect the software calculations of position, size, and orientation.

\section{FEATURE SAMPLING STRATEGY}

The number of points sampled and the pattern in which the points are taken may also affect CMS software reliability. Generally, the mathematical minimum number of points necessary to determine a geometric type is not sufficient for the measurement of an actual feature. 
POINT MEASUREMENT ERROR

The errors in each sampled point induced by the point measurement process may affect the reliability of CMS software. 


\section{Appendix C:}

Special Test Report

\section{Template}




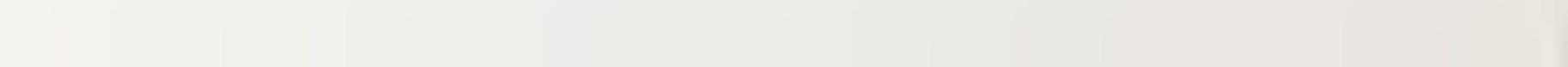


National Institute of Standards and Technology

Gaithersburg, MD 20899-0001

\title{
REPORT OF SPECIAL TEST
}

\author{
for \\ $<$ CMS software $>>$ \\ Submitted by: \\ $<<$ customer $>>$
}

This software package was tested on $x x x$ data sets, representing the following geometry types: line, circle, plane, sphere, cylinder, cone, and torus, and following the test procedures documented in NISTIR $x x x x$. The results of the tests are as follows:

Geometry Type Deviation ( $\mu \mathrm{m})$ Uncertainty ( $\mu \mathrm{m})$
line
circle
plane
sphere
cylinder
cone
torus

Computing Environment:

Measurements performed by:

Test System Version:

Customer's Computing Environment:

Cathleen Diaz

Special Test Date:

Computer Scientist

Report Number:

Approved by:

Neil Christopher

Group Leader

Page 1 of 3

1-301-975-3888

${ }^{\dagger}$ This report gives the results of a single special test conducted by the Manufacturing Systems Integration Division of the National Institute of Standards and Technology. Please call the Manufacturing Systems Integration Division if there are any questions about these results or the distinction between a special test and calibration. 
$<$ short item description $>>$

The reported uncertainty is $<$ explanation of where uncertainty came from $>$. In the case of special tests, NIST will generally assign an estimated "uncertainty" to the result; but it must be recognized by the user that such uncertainty figures are not necessarily supported by a long term data base.

In a rigorous sense, the values reported in this Report of Special Test apply to the software tested only in the computing environment in which it was tested. NIST can provide no assurances that the customer's software will have the same value as reported by NIST when used in the customer's facility at a later date. For a characterization of errors associated with this test see reference 5.

The range of test conditions were as follows:

Geometry T
line
circle
plane
sphere
cylinder
cone
torus

Range of sampling

plan
Range of form errors

\section{Range of measurement error}

This Special Test was carried out as follows. NIST generated data sets simulating the ranges of test conditions described above. NIST also generated reference fit results using:

NIST Algorithm Testing System Internal Algorithms

$\square$ Other:

The customer received the NIST-generated data sets in ASCII format and generated corresponding fit results using the software under test. NIST then compared each of the customer's fits to the reference fit for the corresponding data set using procedures set forth in ASME Standard B89.4.10. The reported test results for each geometry type are the maximum observed deviations between the

Special Test Date:

Report Number:

Page 2 of 3 
$<$ short item description $>>$

customer's fits and the reference fits for all data sets corresponding to that geometry type.

Detailed data concerning this Special Test are available from NIST on request.

$<<$ special information $>>$

For detailed descriptions of the technical approach used for these test services and specifics on the test procedures see the following references.

[1] ASME B89.4.10-199x, Draft, Methods for Performance Evaluation of Coordinate Measuring System Software, American Society of Mechanical Engineers, New York, NY.

[2] Diaz, C., NISTIR 5686, 1995, Algorithm Testing and Evaluation Program for Coordinate Measuring Systems: Testing Methods, Gaithersburg, MD. .

[3] Diaz, C., NISTIR 5137, 1993, User's Guide for the Algorithm Testing System/Version 1.1, Gaithersburg, MD.

[4] Diaz, C., and Hopp, T., Evaluation of Software for Coordinate Measuring Systems, proceedings of the 1995 SME Clinic, CMMs Week, June 5-8, Society of Manufacturing Engineers, Dearborn, MI; proceedings of the 1995 Interface Symposium, June 21-24, Interface Foundation of North America, Carnegie Mellon University, Pittsburgh, PA.

[5] Hopp, T., Performance Measures for Geometric Fitting in the NIST Algorithm Testing and Evaluation Program for Coordinate Measuring Systems, 1995, accepted for publication in the NIST Journal of Research, Gaithersburg, MD.

[6] Rosenfeld, D., NISTIR 5674, 1995, User's Guide for the Algorithm Testing System Version 2, Gaithersburg, MD,

[7] Rosenfeld, D., NISTIR xxxx, Reference Manual for the Algorithm Testing System Version 2, Gaithersburg, MD, in preparation.

Special Test Date:

Report Number:

Page 3 of 3 



\section{References}

1. ASME, 1994, ASME B89.4.10-199x, Methods for Performance Evaluation of Coordinate Measuring System Software, Draft, American Society of Mechanical Engineers, New York, NY.

2. Hopp, Theodore H., 1995, Performance Measures for Geometric Fitting in the NIST Algorithm Testing and Evaluation Program, accepted for publication in the NIST Journal of Research, Gaithersburg, MD.

3. Rosenfeld, David A., 1995, NISTIR xxxx, Reference Manual for the Algorithm Testing System Version 2, Gaithersburg, MD, in preparation.

4. Rosenfeld, David A., 1995, NISTIR 5674, User's Guide for the Algorithm Testing System Version 2, Gaithersburg, MD.

\section{Recommended Reading}

Algeo, Mary E. A., and Hopp, Theodore H., 1992, NISTIR 4740, Form Error Models of the NIST Algorithm Testing System, Gaithersburg, MD.

Cox, M.G., 1992, Improving CMM Software Quality, NPL Report DITC 194/92, National Physical Laboratory, Middlesex, U.K.

Cox, M.G., and Forbes, A.B., 1992, Strategies for Testing Form Assessment Software, NPL Report DITC 211/92, National Physical Laboratory, Middlesex, U.K.

Diaz, Cathleen, 1994, NISTIR 5366, Concept for an Algorithm Testing and Evaluation Program at NIST, January, Gaithersburg, MD.

Diaz, Cathleen, 1993, NISTIR 5137, User's Guide for the Algorithm Testing System/Version 1.1, Gaithersburg, MD.

Diaz, Cathleen, 1995, NISTIR xxxx, NIST Special Test Service: The Algorithm Testing and Evaluation Program for Coordinate Measuring Systems, Gaithersburg, MD, in preparation.

Diaz, Cathleen, and Hopp, Theodore H., 1995, Evaluation of Software for Coordinate Measuring Systems, Proceedings of the 1995 SME Clinic, CMMs Week, June 5-8, Society of Manufacturing Engineers, Dearborn, MI; Proceedings of the 1995 Interface Symposium, June 21 - June 24, Interface Foundation of North America, Carnegie Mellon University, Pittsburgh, PA.

Feng, Shaw C., and Hopp, Theodore H., A Review of Current Geometric Tolerancing Theories and Inspection Data Analysis Algorithms, 1991, NISTIR 4509, National Institute of Standards and Technology, Gaithersburg, MD. 
GIDEP, 1988, GIDEP Alert X1-A88-01, Walker, R., CMM Form Tolerance Algorithm Testing, Government-Industry Data Exchange Program, DOD, Washington, D.C.

Hopp, Theodore H., 1993, Computational Metrology, Manufacturing Review, Vol. 6, No. 4, pp. 295 - 304, American Society of Mechanical Engineers, New York.

ISO, 1993, Guide to the Expression of Uncertainty in Measurement, International Organization for Standardization, Geneva, Switzerland.

Taylor, B. N., and Kuyatt, C. E., 1994, Guidelines for Evaluating and Expressing the Uncertainty of NIST Measurement Results, NIST Technical Note 1297, 1994 Edition, National Institute of Standards and Technology, Gaithersburg, MD.

Wäldele, F., Bittner, B., Busch, K., Drieschner, R., Elligsen, R., 1993, Testing of Coordinate Measuring Machine Software, Precision Engineering, Vol. 15, pp. 121-123. 



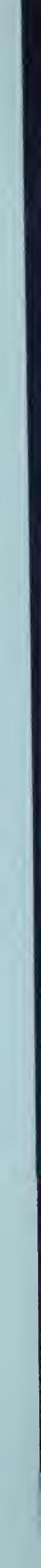

